\title{
Self-Esteem Is the Sense of Personal Worth and Competence That Persona Associate with Their Self - Concepts
}

\author{
Mr. Abhishek Sharma \\ Associate professor, mental health nursing department llrine, gdh.jalandhar, punjab
}

\begin{abstract}
:
Aim: to determine difference of self esteem level among B.ScNursing students $4^{\text {th }}$ year and GNM interns.

Objectives: Self - esteem is a widely used concept both in popular language and in Psychology. It refers to an individual's sense of his or her value or worth, or the extent to which a person value, approves of, appreciates, prizes, or like him or herself.

Methodology: A comparative study was conducted in the Rajeev Educational Trust at Hassan on 40 students in both groups of final year B.Sc Nursing students and final year GNM students selected through simple random method. The multidimensional self esteem questionnaire

The study was conducted in the Rajeev Educational Trust at Hassan offered different type courses The final year B.Sc. nursing class 70 students are studyiwas used to collect the data.

Results: For P.S.E in B.Sc. nursing mean 32.33, S.D 3.19 \& for G.N.M students 27.33 \& 3.86 with 't' value at 6.32. F.S.E in B.Sc. nursing mean 33.20, S.D 2.95 \& for G.N.M 27.0 \& 4.10 with 't' value 7.76. And for P.S.E mean 32.00, S.D $2.62 \&$ in G.N.M 26.78 \& 4.12 with ' $t$ ' value 6.76
\end{abstract}

Key words:Assess, B.Sc. Nursing students, Comparative, G.N.M. intern Students, self esteem.P-personl,Ffamily,pr-professional

\section{Introduction}

Self - esteem is a widely used concept both in popular language and in Psychology. It refers to an individual's sense of his or her value or worth, or the extent to which a person value, approves of, appreciates, prizes, or like him or herself. The most broad and frequently cited definition of self -esteem with in Psychology is Rosenberg's (1965) who described is as a favorable or unfavorable attitude toward the self.Self esteem is generally considered the evaluative component of the self concept, a broader representation of the self that includes Cognitive and behavioral aspects as well as evaluative or affective ones (Blascovich and Toamka, 1991). It is also widely assumed that self-esteem function as a trait, that is, it is stable across time with in individual. Self-esteem has been related both to socioeconomic status and to various aspects to health and health-related behaviors. ${ }^{1}$

Self-esteem is the subjective measure of a person's values - the worth that one believes one has as an individual. Psychologists since William James have attempted to define this self-appraisal in such as way as to measure it objectively, but with only mixed results. Low self-esteem has been implicated in bullying, although research suggests that people are more likely to use violence when they possess an unrealistically high selfesteem. The expectation that self-esteem was important in success, both academically in school and in life, led to efforts to increase self-esteem in students. However, such increases, without concomitant improvements in skills or increases in knowledge are as false as those of bullies, with equally unfortunate results. True selfesteem reflects the real value of a person, which does not depend on any specific ability compared to others, but rather resides in their integrity as a person who fulfills their potential with regard to their unique talents and abilities, who relates harmoniously with others, and who is responsible in relationship to their environment ${ }^{2}$.

Schools can influence their students' self-esteem through the attitudes they foster toward competition and diversity and their recognition of achievement in academics, sports, and the arts. By middle childhood, friendships have assumed a pivotal role in a child's life. Studies have shown that school-age youngsters spend more time with their friends than they spend doing homework, watching television, or playing alone. In addition, the amount of time in which they interact with their parents is greatly reduced from when they were younger. At this stage, social acceptance by a child's peer group plays a major role in developing and maintaining self-esteem ${ }^{3}$.

Self-esteem is important in every sphere of life and can be considered a basic human need. Self-esteem increases the level of personal security and has been described as a protective factor against risk behaviors. However, our data indicate increased drug consumption among young people with higher self-esteem. Given the importance of the topic and the novelty of our results, in future studies we intend to broaden the sample and 
Self-esteem is the sense of Personal worth and competence that persona associate with their self...

perform probabilistic stratified sampling in order to extrapolate the results to the entire population of the University of Almería ${ }^{4}$.

\section{Problem Statement}

\section{Research Methodology}

A Comparative Study to assess the self esteem level between the final year B.Sc. Nursing and final year G.N.M students of Rajeev educational trust at Hassan.

\section{Research Setting}

The study was conducted in the Rajeev Educational Trust at Hassan. The researcher selected 40 final year B.Sc. nursing and 40 G.N.M. students by using simple random sampling technique.The investigator distributed structured questionnaire to the students.

\section{Description Of Tool}

Part - I

The demographic data in relation to age, sex, religion, types of family place of residence, monthly income, pre exam score and stress in exam.

\section{Part - II}

The multidimensional self esteem questionnaire prepared by the Dr.SKarunanidhi (1996), Professor, Department of Psychology, university of madras. It consists of 30 Positive statements. Each statement has four alternative responses such as 'always', Most of the time', sometimes' and 'never' The Inventory measures 3 dimensions of self-esteem: personal - 10 items, family 10 items and professional - 10 items.

Higher the scores in each dimensional the level of self-esteem is high. Items are scored, as it is follow.

\section{Score Interpretation}

The score item in the Dr. S. Karunanidhi modified self esteem rating scale is as follows.

Always: 4

Most of the time: 3

Some time: 2

\section{Never 1}

The total score range categories is:-

Inadequate; $>50$

Moderately adequate: $51-70$

Adequate: $<70$

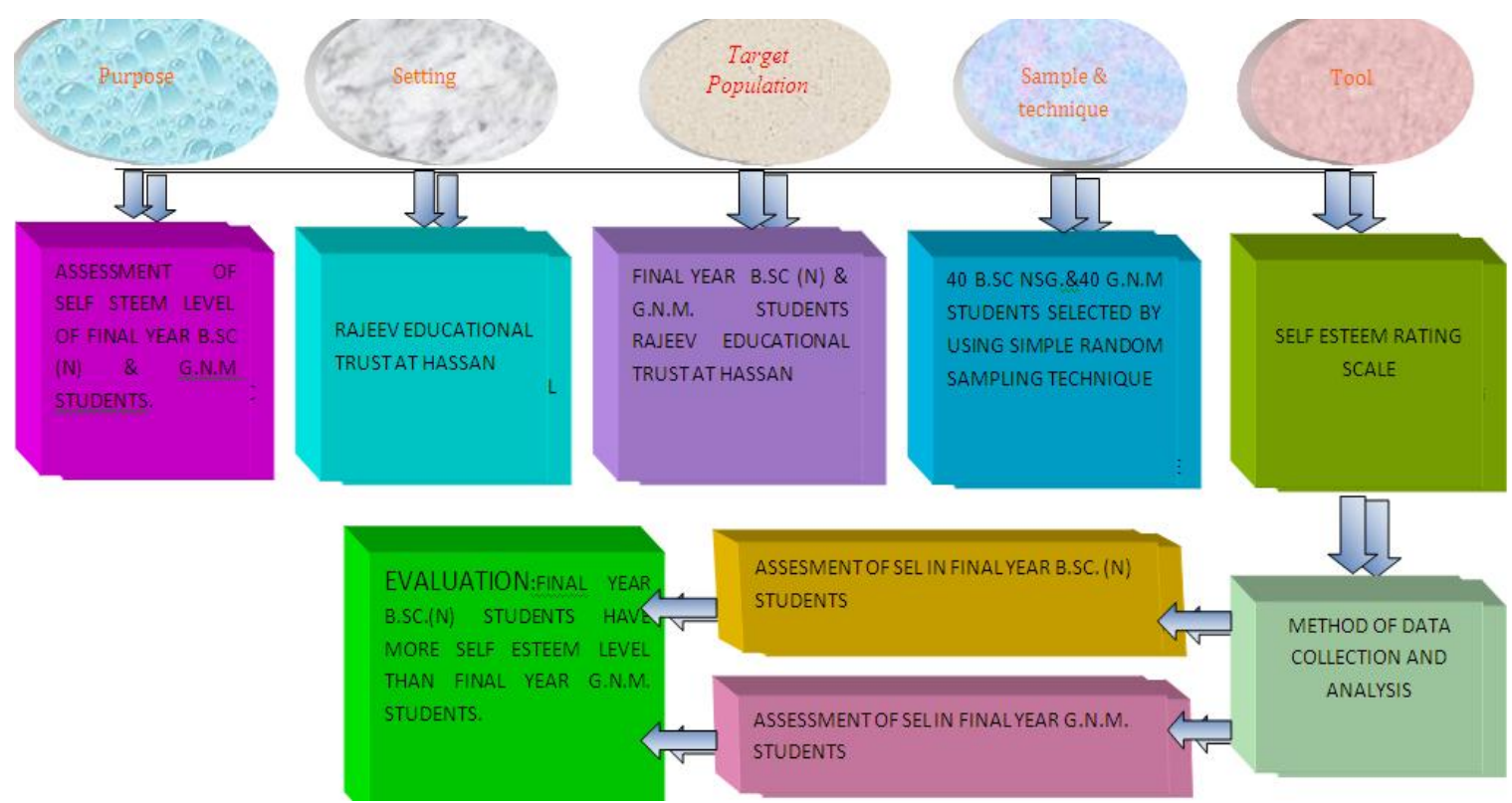


Self-esteem is the sense of Personal worth and competence that persona associate with their self...

III. Result

Table -1Percentage distribution of self esteem level among final year B.Sc(nursing) students.

\begin{tabular}{|c|c|c|c|}
\hline Type Of Assessment Data & Inadequate & Moderately adequate & Adequate \\
\hline Personal Self Esteem & $0(0.0 \%)$ & $111\left(\begin{array}{llll}2 & 7 & 5 \%\end{array}\right)$ & $29(72.5 \%$ \\
\hline Family self esteem & $0(0.0 \%)$ & $10(25$. & $30(75.0 \%)$ \\
\hline Professional self esteems & $1(2.5 \%)$ & $11(27$. & $28(70.0 \%)$ \\
\hline
\end{tabular}

Table no 1 reveals the S.E.L. of the final year B.Sc.nursing student. As table vision show that Personal Self Esteem was inadequate in $0 \%$ students, moderately adequate in $27.5 \%$ and adequate $72.5 \%$. Family Self Esteem was inadequate $0.0 \%$, moderately adequate $2.5 \%$ and adequate $75 \%$. Where asPr.S.E. were inadequate $2.5 \%$, moderately adequate $27.5 \%$ and $70 \%$ adequate.

Table -02Percentage distribution of self esteem level among GNMIntern students.

\begin{tabular}{|c|c|c|c|}
\hline A s s e s s ment & In a d e qua te & Moderately adequate & A d e $q u$ a t e \\
\hline $\begin{array}{llllllllllllllllll} & \text { e } & \mathbf{r} & \mathbf{s} & \mathbf{o} & \mathbf{n} & \mathbf{a} & \mathbf{l} & \mathbf{S} & \mathbf{e} & \mathbf{l} & \mathbf{f} & \mathbf{E} & \mathbf{s} & \mathbf{t} & \mathbf{e} & \mathbf{e} & \mathbf{m}\end{array}$ & $2 \quad\left(\begin{array}{lllll} & 5 & 0 & 0 & \%\end{array}\right)$ & $31\left(\begin{array}{lllll}7 & 7 & 5 \%\end{array}\right.$ & $7(117.5 \%)$ \\
\hline 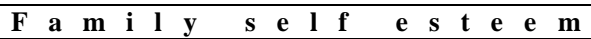 & $1)(2$ & $33(82$ & $6(15$ \\
\hline Profession a l s e lf - e st e e m s & $\%$ & $32(8$ & $5(12$ \\
\hline
\end{tabular}

Table no 02 reveals the SEL of the final year G.N.M student that P.S.E were inadequate in 5\%, Moderately adequate in $77.5 \%$ and adequate $17.5 \%$. F.S.E was inadequate $2.5 \%$. And Moderately adequate $82.5 \%$ and adequate $15 \%$. Whereas P.S.E were inadequate $7.5 \%$. Moderately adequate $80 \%$ and adequate $12.5 \%$.

Table-3Comparisons of overall self esteem score between final years B.Sc.nursing \& G.N.M Intern student.

\begin{tabular}{|c|c|c|c|c|}
\hline Assess ent & No, of students & $\begin{array}{l}\text { B } \\
\text { Mean } \pm \text { SD }\end{array}$ & 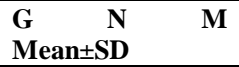 & $\begin{array}{l}\text { St ud ent independent } \\
\text { t-test }\end{array}$ \\
\hline $\begin{array}{l}\text { O v e r a } 11 \\
\text { Score }\end{array}$ & 4 & $97.53 \pm 7.07$ & $81.10 \pm 11.50$ & $\mathrm{t}=7.69 \quad \mathrm{P}=0.001 * * *$ \\
\hline
\end{tabular}

Table -3 shows B.Sc. nursing students having large mean than G.N.M students. The B.Sc. nursing mean score is 97.53 with S.D 7.07 \& G.N.M score 81.10 with S.D 11.50. The' $t$ ' value is 7.69. that is significant at $\mathrm{P}<0.001$ level.

Table-4Comparisons of mean percentage self esteem level in different category of final year B.Sc. nursing\&

G.N.M Intern students.

\begin{tabular}{|c|c|c|c|c|c|}
\hline \multirow{2}{*}{$\begin{array}{llllllll}C & \text { a } & \text { t } & \text { e } & \text { g } & \text { o } & \mathbf{r} & \mathbf{y}\end{array}$} & B & c & G & $\mathbf{M}$ & \multirow[t]{2}{*}{ Chi-square test } \\
\hline & No. of students & $\%$ & No. of students & $\%$ & \\
\hline In a d e quate & 1 & 2.5 & 5 & 12.5 & \multirow{3}{*}{$\begin{array}{l}\mathrm{X} 2=27.03 \\
\mathrm{P}=0.001 * * *\end{array}$} \\
\hline Moderately adequate & 1 & 25.0 & 2 & 72.5 & \\
\hline A d e qua t e & 29 & 72.5 & 6 & 15.0 & \\
\hline
\end{tabular}

Table-4depicts the difference between final year B.Sc. nursing \& G.N.M students according to category. Inadequate category B.Sc. nursing mean $2.5 \%$ \& G.N.M $12.5 \%$. For moderately adequate category B.Sc. nursing student mean $25 \%$ \& G.N.M $72.5 \%$. Where as for adequate category B.Sc. mean $72.5 \%$ \& G.N.M $15 \%$. The Chi square value is 27.03 . That is Significant at $\mathrm{P}<0.001$ level.

Table- 5The net difference between final year b.sc. Nursing and g.n.m. Intern students.

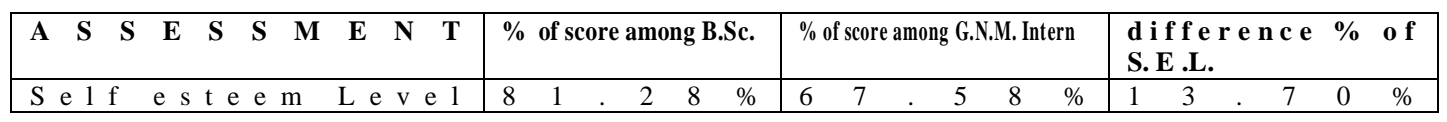

Table no.-5 shows the net difference between Final year B.Sc. nursing and GNM students. It reveals the B.Sc. nursing students self-esteem level score is $81.28 \%$ \& G.N.M students $67.58 \%$. It shows that B.Sc. nursing students have $13.7 \%$ moreself esteem than GNM students.

\section{Major Finding Of The Study}

The demographic information of final B.Sc.nursing \& G.N.M who are participated for the study. In demographic mean percentage for age 20 to 22 years in B.Sc.nursing is $45 \%$ \& for G.N.M 65\%, 22-24 for B.Sc.35\% for G.N.M \& same as for 24-26 years for B.Sc.is $20 \%$ and for G.N.M $0 \%$ with 9.47 Chi square value $(\mathrm{p}=0.01)$. The sex mean percentage for male B.Sc.nursing student $45 \%$ and $42.5 \%$ for G.N.M \& for female $55 \%$ for B.Sc.nursing student \& $57.5 \%$ for G.N.M with 0.05 Chi square value ( $\mathrm{p}=0.82$ ). In religion Hindu, Muslim \& 
Self-esteem is the sense of Personal worth and competence that persona associate with their self...

Christian B.Sc.nursing student mean percentage 37.5\%, 2.5\%, 60\% \& for G.N.M 32.5\%, $0.07 \%$ \& $67.5 \%$ with 1.31 Chi square value $(\mathrm{p}=0.52)$.For residency urban B.Sc.nursing student mean percentage $57.5 \%$ \& rural $42.5 \%$ $\&$ for G.N.M $62.5 \%$ and 37.5 with 0.21 Chi square value $(\mathrm{p}=0.65)$. The nuclear family B.Sc.nursing students The family income mean percentage is following <Rs 5,000, 12.5 , from $5000-10000$ is $47.5 \%$ \& $>10,00040.0 \%$ \& for G.N.M student $60 \%, 40 \%$ \& $0 \%$ with 28.71 Chi square value $(\mathrm{p}=0.001)$. The pre exam is score mean percentage for $50-60$ for B.Sc. is $50 \%$ an for G.N.M $52.5 \%, 61-70 \%$ for B.Sc. is $40 \%$ \& G.N.M $32.5 \%$, who have $>70 \%$ for B.Sc. Nursing $10 \%$ \& $15 \%$ for G.N.M with 10.74 Chi square value ( $\mathrm{p}=0.69)$. Mean percentage $52.5 \%$ \& for G.N.M $62.5 \%$ \& for joint family B.Sc.Nursing have $47.5 \%$ \& $37.5 \%$ for G.N.M student with 0.81 Chi square value $(\mathrm{p}=0.37)$. Where as stress in exam for 'yes' means percentage for B.Sc.Nursing is $52.5 \%$ and $67.5 \%$ for GNM student for 'NO' $47.5 \%$ B.Sc. nursing and $32.5 \%$ for GNM students with 1.88 Chi-square value $(\mathrm{p}=0.17)$.

\section{Discussion}

The aims of the study are to assess the self-esteem level and compared between the final year B.Sc. nursing and G.N.M. students who are studying Rajeev Educational Trust at Hassan.

H1: There is a significant difference in the self-esteem level between the final year B.Sc. Nursing and final year G.N.M students.

H 2: The final year B.Sc. nursing students have higher self-esteem level than final year G.N.M students.

Different type assessment of self -esteem level among final year B.Sc. nursing students was having 80.8\%, P.S.E $83.0 \%$ F.S.E and $80.0 \%$ P.S.E., having more self-esteem in F.S.E. assessment than other assessment.

Overall SEL percentage assessment of the final year B.Sc. Nursing students was $81.28 \%$. P.S.E. was inadequate in $0 \%$ students, moderately adequate in $27.5 \%$ and adequate $72.5 \%$. FSE was inadequate $0.0 \%$ and moderately adequate $2.5 \%$ and adequate $75 \%$ students.

The percentage of S.E.L of B.Sc.nursing final year students It revealed that frequency \& percentage of students. Such as 1 student have $2.5 \%$ of inadequate S.E.L, 10 student have $25 \%$ moderately adequate S.E.L \& 29 Student have $72.5 \%$ adequate self esteem level.

Self esteem level among final year G.N.M students were having 68.3\% P.S.E, 67.5\% F.S.E and $66.9 \%$ Pr.S.E. The students are having more self-esteem in P.S.E. assessment than other assessment.

The overall S.E.L score of G.N.M student. was $67.58 \%$.Table no 10 reveals the S.E.L. of the final year G.N.M student. As table vision show that P.S.E were inadequate in 5\% students. Moderately adequate in $77.5 \%$ and adequate $17.5 \%$. F.S.E was inadequate $2.5 \%$. And Moderately adequate $82.5 \%$ and adequate $15 \%$. Where asPr.S.E were inadequate $7.5 \%$. Moderately adequate $80 \%$ and adequate $12.5 \%$.

The percentage of S.E.L of final year G.N.M student. It reveals the frequency \& percentage of students. It shows one student have $12.5 \%$ of inadequate S.E.L, 29 student have $72.5 \%$ moderately adequate S.E.L \& 6 Student have $15.0 \%$ adequate self esteem level.

\section{ComparesionOf The Self-Esteem Level Between The Final Year B.Sc. Nursing And G.N.M Students}

The mean percentage and standard deviation of both group with ' $t$ ' value of the self esteem level. For P.S.E in B.Sc. nursing mean 32.33, S.D $3.19 \&$ for G.N.M students $27.33 \& 3.86$ with ' $t$ ' value at 6.32.F.S.E in B.Sc. nursing mean 33.20, S.D 2.95 \& for G.N.M $27.0 \& 4.10$ with ' $t$ ' value 7.76.And for Pr.S.E mean 32.00, S.D $2.62 \&$ in G.N.M $26.78 \& 4.12$ with 't' value 6.76 .

The comparison of over all self-esteem level score of final year B.Sc. nursing \& G.N.M students. The B.Sc. nursing students having large mean than compare to G.N.M students. Table reveal the B.Sc. nursing mean score is 97.53 with S.D 7.07 \& G.N.M score 81.10 with S.D 11.50. The ' $t$ ' value is 7.69

.The difference between final year B.Sc. nursing \& G.N.M students according to category wise. Inadequate category B.Sc. nursing mean $2.5 \%$ \& G.N.M $12.5 \%$. For moderately adequate category B.Sc. nursing student mean $25 \%$ \& G.N.M $72.5 \%$. Whereas for adequate category B.Sc. mean $72.5 \%$ \& G.N.M $15 \%$. The Chi square value is 27.03. The net difference between Final year B.Sc. nursing and GNM students. It reveals the B.Sc. nursing students self esteem level score is $81.28 \%$ \& G.N.M students $67.58 \%$. It shows that B.Sc. nursing students have $13.7 \%$ more self esteem than GNM students.

\section{Association Of The Mean Self-Esteem Level With Selected Socio Demographic Variables}

It shows the association between demographic variables and their self-esteem level of B.Sc. nursing students. In demographic variable the type of family and pre exam score is closely associated with self-esteem level of final year B.Sc. nursing students. In nuclear family have $0 \%$ inadequate, $4.8 \%$ moderately adequate and 95.2\% adequate self-esteem level. The joint families have 5.3\% inadequate $47.4 \%$ moderately adequate and $47.4 \%$ adequate self-esteem levels with chi value 11.50 . $(\mathrm{p}=0.003 *)$. The pre exam score from $50 \%-60 \%$ for 
Self-esteem is the sense of Personal worth and competence that persona associate with their self...

inadequate $5 \%$ moderately adequate $45 \%$ and $50 \%$ adequate. Whereas $61 \%-70 \%$ is $0.0 \%$ inadequate, $6.3 \%$ moderately adequate and $93.8 \%$ adequate. Same as $>70 \%$ for inadequate $0 \%$, moderately adequate $0.0 \%$ and $100 \%$ adequate with chi square value $10.26 \%$.( $\mathrm{p}=0.04 *)$. The more mark and nuclear family system students having more adequate self esteem level. The statistical significance was calculated using Pearson chi square test.

It shows the association between demographic variables and their self-esteem level of final year GNM students. Nursing student's pre exam score and place of residence are closely associated with their level of selfesteem. The ta place of residency urban mean percentage category wise is $4.0 \%$ in adequate, $72.0 \%$ moderately adequate $\& 24.0 \%$ adequate $\&$ for rural $26.7 \%, 73.3 \% \& 0.0 \%$ with $7.4 \%$ chi square value. $(\mathrm{p}=0.02 *)$. The pre exam score from $50 \%-60 \%$ for inadequate $22.7 \%$ moderately adequate $77.3 \%$ and $0.0 \%$ adequate. Whereas $61 \%-70 \%$ is $0.0 \%$ inadequate, $90 \%$ moderately adequate and $10 \%$ adequate. Same as $>70 \%$ for inadequate $0.0 \%$, moderately adequate $37.5 \%$ and $62.5 \%$ adequate with chi square value $21.43 \% .(\mathrm{p}=0.001 * * *)$. More mark and urban students having more adequate esteem. Statistical significance was calculated using Pearson chi square test.

\section{Conclusion}

According to the study finding the majority of final year B.Sc. nursing students having adequate Self Esteem Level and most of the final year G.N.M. Students having inadequate Self Esteem Level.The final year G.N.M. Students Self Esteem Level is affected by socio demographics variables and in which previous it's mostly affected by previous exam score and place of residency.

\section{Acknowledgement}

I express my gratitude and thanks towards all who have directly or indirectly helped me to complete this study and their support in each major step of the study.

\section{References}

[1]. Nancy Adler and Judith Stewart, "Collaboration with the Psychosocial working Group" March 2004.

[2]. Hure D "Psychosocial problem among students". Apr 1993; 7(3): 70-76.

[3]. Elit M "self esteem through the student attitude". Apr 2002; 18(3): 120-126.

[4]. $\quad$ Ruiz-Muñoz Adel M. "Self-esteem level and correlation to risk behaviour of students at" J Contemp Dent Pract. 2008 Jan 1; $9(1): 38-45$. 